\title{
Endogenous Sulfur Dioxide Improves the Survival Rate of Sepsis by Improving the Oxidative Stress Response during Lung Injury
}

\author{
Zhiwei Liu $\mathbb{D}^{1},{ }^{1}$ Jiaqi Gao $\mathbb{D}^{1},{ }^{1}$ Xin Ye $\mathbb{D},^{2}$ Cong Wang $\mathbb{D}$, ${ }^{1}$ and Bin Zhao $\mathbb{D}^{1}$ \\ ${ }^{1}$ Department of Emergency Medicine, Beijing Jishuitan Hospital, Beijing 100035, China \\ ${ }^{2}$ Department of Cardiology, Beijing Jishuitan Hospital, Beijing 100035, China \\ Correspondence should be addressed to Cong Wang; congerwang1975@sina.com and Bin Zhao; zhaobin60@aliyun.com
}

Received 27 October 2021; Revised 13 December 2021; Accepted 4 February 2022; Published 27 February 2022

Academic Editor: Lei Song

Copyright (C) 2022 Zhiwei Liu et al. This is an open access article distributed under the Creative Commons Attribution License, which permits unrestricted use, distribution, and reproduction in any medium, provided the original work is properly cited.

\begin{abstract}
Objective. To explore the regulation of endogenous sulfur dioxide on oxidative stress in lung injury induced by sepsis. Method. Forty male Sprague Dawley rats were divided into control, sepsis, sepsis $+\mathrm{SO}_{2}$, and $\mathrm{SO}_{2}$ group randomly used to observe survival rate. The other group of twenty-eight rats were randomly divided as the same manner for mechanism research. The number of WBCS and the percentage of PMN cells were calculated. The microphotographs of morphological changes and the index of quantitative assessment (IQA) of lung tissues were calculated. The ratio of wet/dry (W/D) of lung tissues was calculated. Levels of $\mathrm{H}_{2} \mathrm{O}_{2}, \mathrm{MDA}$, NO, MPO, SOD, GSH-px, and TNF- $\alpha$ in plasma and lung tissues were measured. Result. The number of WBCS and the percentage of PMN cells decreased in sepsis $(p$ all $<0.05)$, and rebound in sepsis $+\mathrm{SO}_{2}(p$ all $<$ $0.05)$. The IQA and W/D of lung tissues increased in sepsis ( $p$ for $W / D<0.05)$, and decreased in sepsis $+\mathrm{SO}_{2}(p$ all $<0.05)$. $\mathrm{H}_{2} \mathrm{O}_{2}$ and MDA of plasma and lung tissues increased in sepsis $(p$ all $<0.05)$ and rebound in sepsis $+\mathrm{SO}_{2}\left(p\right.$ for $\mathrm{H}_{2} \mathrm{O}_{2}$ of plasma and lung tissues <0.05). NO and MPO of plasma and lung tissues increased in sepsis ( $p$ for NO and MPO of lung tissues $<0.05)$ and rebound in sepsis $+\mathrm{SO}_{2}(p$ all $<0.05)$. SOD of plasma and lung tissues in sepsis group decreased $(p$ all $<0.05)$ and increased in sepsis $+\mathrm{SO}_{2}(p$ all $<0.05)$. GSH-px of plasma and lung tissues decreased in sepsis $(p$ for plasma $<0.05)$ and increased in sepsis $+\mathrm{SO}_{2}$ ( $p$ for GSH-px of lung tissues <0.05). TNF- $\alpha$ of plasma and lung tissues increased in sepsis $(p$ all $<0.05$ ) and decreased in sepsis $+\mathrm{SO}_{2}$ ( $p$ for lung tissue $<0.05$ ). Conclusion. Endogenous sulfur dioxide improves the survival rate of sepsis by improving the oxidative stress response during lung injury.
\end{abstract}

\section{Introduction}

Sepsis could be induced by severe trauma, injury, shock, and major surgery. Sepsis may be developed to septic shock and multiple organ dysfunction. Sepsis is a common clinical disease and a common cause of death in patients. Lung injury is the most common complication and the most fatal complication [1]. Oxidative stress response is the key pathogenesis of lung injury induced by sepsis [2]. Endogenous $\mathrm{SO}_{2}$ acts as a protective role during the lung injury induced by ischemiareperfusion [3]. Endogenous $\mathrm{SO}_{2}$ plays a protective role in acute lung injury caused by oleic acid by inhibiting oxidative stress [4]. However, whether endogenous sulfur dioxide can protect the lung injury of septic rats by improving the oxidative stress response, there is no relevant research at present. Therefore, this study puts forward the hypothesis that endogenous sulfur dioxide plays a protective role in the pathological process of sepsis by inhibiting the oxidative stress response of lung tissue during lung injury in sepsis. Therefore, this study took sepsis rats caused by cecal ligation and puncture to probe the regulation of endogenous sulfur dioxide about oxidative stress response in the process of septic lung injury. 


\section{Materials and Methods}

2.1. Animal and Groups. This study is a randomized controlled animal experiment. This research proposal was approved by the ethics committee of Beijing Jishuitan Hospital. The ethics code of this research is Jilunke Shenzi No. 202006-26. A total of 68 Sprague-Dawley male rats at 8week-old and weighed 200-250 g were bought from Animal Laboratory in the first hospital of Peking University. The sample size of the experiment depends on previous research [4].

2.1.1. Rats Used to Observe Survival Rate. 40 rats were used to observe the survival rate. They were randomly divided into four groups: control group, sepsis group, sepsis $+\mathrm{SO}_{2}$ group, and $\mathrm{SO}_{2}$ group. There were 10 rats in each group. After the completion of the operation, the 4 groups have all been observed for 72 hours, and the ratio of survival at $12,24,36,48$, and 72 hours after operation in rats was counted.

2.1.2. Rats Allocated for Mechanism Research. The other groups of 28 male SD rats allocated for mechanism research were also randomly divided into four groups in the same manner, with four groups, i.e., control group, sepsis group, sepsis $+\mathrm{SO}_{2}$ group, and $\mathrm{SO}_{2}$ group. There were 7 rats in each group. The rats bled to death from abdominal aorta. These rats were anesthetized by $12 \%$ urethane $1 \mathrm{~mL} / \mathrm{kg}$ intraperitoneally, after observation for 12 hours after the operation.

2.1.3. Animal Model Preparation. For the rats in control group, the only treatment is opening the abdomen, turning the intestines, and then, closing the abdomen. The rats in $\mathrm{SO}_{2}$ group were treated with an intraperitoneal sulfur dioxide donor $\left(\mathrm{Na}_{2} \mathrm{SO}_{3} / \mathrm{NaHSO}_{3}\right)$ of $0.5 \mathrm{~mL} / \mathrm{kg} 30$ minutes before the laparotomy was performed as an endogenous sulfur dioxide donor, and the rest of the operations were the same as those in control group. The $\mathrm{Na}_{2} \mathrm{SO}_{3} / \mathrm{NaHSO}_{3}$ solution was freshly prepared with physiological saline at $3: 1$ $(0.54: 0.18 \mathrm{mmol} / \mathrm{kg})$. Rats in sepsis group were subjected to cecal ligation and perforation after laparotomy as follows [5]. The surgical operation method of cecal ligation and puncture was as follows: the animals were kept in an SPF environment and fasted 12 hours before the operation. After intraperitoneal injection of $13 \%$ pentobarbitone $(1 \mathrm{~mL} / \mathrm{kg})$, they had experienced anesthetized fixation, shave, and alcohol disinfection. A $1 \mathrm{~cm}$ incision was made along the midline of the abdomen, the cecum exposed, and then ligated $1 / 2$ of the cecum under the ileocecal valve. A 21-gauge needle is used to penetrate the cecum twice, and place a $3 \mathrm{~mm}$ wide rubber drainage strip through the cecum to prevent the needle hole from closing. After the cecum is admitted, the abdomen was closed and sutured layer by layer. The operation was strictly aseptic. Immediately after the surgery, $50 \mathrm{~mL} /$ $\mathrm{kg}$ normal saline was used for antishock. After the operation, the animals drank and ate freely. Rats in sepsis $+\mathrm{SO}_{2}$ group were injected sulfur dioxide donor $\left(\mathrm{Na}_{2} \mathrm{SO}_{3} / \mathrm{NaHSO}_{3}\right)$ $0.5 \mathrm{~mL} / \mathrm{kg} 30$ minutes before the cecal ligation and perforation intraperitoneally. And the rest of the operations were the same as those in sepsis group. After observation time, the rats were bled to death from abdominal aorta with anesthetization by $12 \%$ urethane $1 \mathrm{~mL} / \mathrm{kg}$ intraperitoneally.

2.2. Morphology of Lung Tissue under Light Microscope and Semiquantitative Assessment of Lung Injury (IQA). The middle lobe of the right lung was stored, stained by HE, and observed by a 400x light microscope. Ten fields of view were taken from each slice for semiquantitative scoring of lung injury. Evaluation indicators included alveolar edema, inflammatory cell infiltration, and formation of the hyaline membrane. Each index was divided into four levels: normal, mild, moderate, and severe, which are scored as $0,1,2$, and 3 correspondingly.

2.3. The Weight Ratio of Wet/Dry of Lung Tissue. The wet weight of the lung was recorded as soon as the lung was separated, and it was placed in $80^{\circ} \mathrm{C}$ incubator until the weight did not change and then recorded the dry weight. At last, the weight ratio of wet/dry was calculated.

2.4. Level of Oxidative Stress in Both Plasma and Lung Tissues. Levels of hydrogen peroxide $\left(\mathrm{H}_{2} \mathrm{O}_{2}\right)$, malondialdehyde (MDA), nitric oxide (NO), and myeloperoxidase activity (MPO) in both plasma and lung tissues in each group were detected. Total glutathione oxidase (GSH-px) level and superoxide dismutase (SOD) activity in both plasma and lung tissues in each group were detected. All the above indicators were detected by ELISA.

2.5. Statistics. The data was statistically analyzed by using SPSS22.0 software. The data were recorded as mean \pm standard deviation (mean $\pm \mathrm{SD}$ ). The comparison among the four groups was performed by one-way ANOVA, and $p<0.05$ is considered as of statistical significance.

\section{Results}

3.1. The Survival Rate of Rats in Each Group. The survival rates of rats in sepsis group were lower than the control group at $36 \mathrm{~h}, 48 \mathrm{~h}$, and $72 \mathrm{~h}$ after the operation $(p=0.015$, 0.001 , and 0.001 , respectively). The survival rates of rats in sepsis $+\mathrm{SO}_{2}$ group were improved compared to the sepsis group at $12 \mathrm{~h}, 24 \mathrm{~h}, 36 \mathrm{~h}, 48 \mathrm{~h}$, and $72 \mathrm{~h}$ after the operation, but the difference were not statistically significant $(p=1.000,1.000,0.371,0.171$, and 0.171 , respectively, Figure 1, Table 1).

3.2. The WBC and Neutrophil of Rats in Each Group. The blood WBC of rats in control group, sepsis group, sepsis $+\mathrm{SO}_{2}$ group, and $\mathrm{SO}_{2}$ group were $3.07 \pm 1.074 \times 10^{9} / \mathrm{L}$, $1.61 \pm 0.538 \times 10^{9} / \mathrm{L}, 3.66 \pm 0.790 \times 10^{9} / \mathrm{L}$, and $2.69 \pm 0.278$ $\times 10^{9} / \mathrm{L}$, respectively. The white blood cell count of rats in sepsis group was lower than the control group $(p=0.001)$. The white blood cell count of rats in sepsis $+\mathrm{SO}_{2}$ group was higher than the sepsis group ( $p=0.000$, Figure 2$)$. The percentages of neutrophils in the blood of rats in control group, sepsis group, sepsis $+\mathrm{SO}_{2}$ group, and $\mathrm{SO}_{2}$ group were 17.81 $\pm 7.34 \%, \quad 4.40 \pm 1.66 \%, 31.0 \pm 5.85 \%$, and $20.5 \pm 5.85 \%$, respectively. The percentage of blood neutrophils in sepsis group was lower than the control group $(p=0.000)$. 


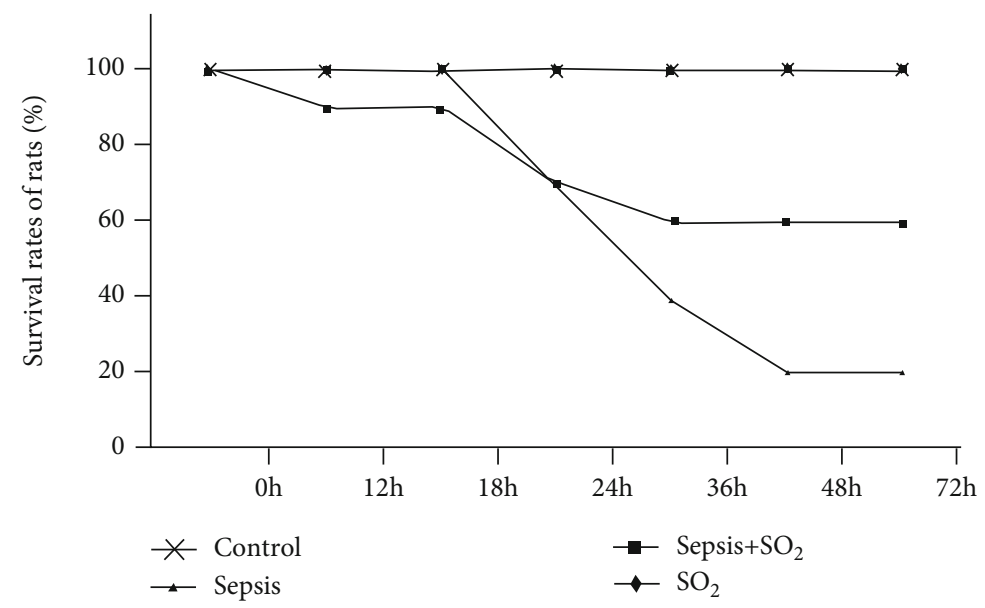

Figure 1: The survival rates of rats in each group.

TABLE 1: The survival rates of rats in each group.

\begin{tabular}{|c|c|c|c|c|c|c|c|c|c|}
\hline \multirow{2}{*}{ After CLP } & & \multicolumn{2}{|c|}{ Group } & \multirow{2}{*}{$\chi^{2}$} & \multirow{2}{*}{$p$} & \multicolumn{2}{|c|}{ Group } & \multirow{2}{*}{$x^{2}$} & \multirow{2}{*}{$p$} \\
\hline & & Sepsis & Control & & & Sepsis & Sepsis $+\mathrm{SO}_{2}$ & & \\
\hline \multirow{2}{*}{$12 \mathrm{~h}$} & Death & 0 & 0 & & & 0 & 1 & & \multirow{2}{*}{1.000} \\
\hline & Survival & 10 & 10 & & & 10 & 9 & & \\
\hline \multirow{2}{*}{$24 \mathrm{~h}$} & Death & 3 & 0 & \multirow{2}{*}{1.569} & \multirow{2}{*}{.210} & 3 & 3 & \multirow{2}{*}{0.000} & \multirow{2}{*}{1.000} \\
\hline & Survival & 7 & 10 & & & 7 & 7 & & \\
\hline \multirow{2}{*}{$36 \mathrm{~h}$} & Death & 6 & 0 & \multirow{2}{*}{5.952} & \multirow{2}{*}{.015} & 6 & 4 & \multirow{2}{*}{$.800^{\mathrm{a}}$} & \multirow{2}{*}{.371} \\
\hline & Survival & 4 & 10 & & & 4 & 6 & & \\
\hline \multirow{2}{*}{$48 \mathrm{~h}$} & Death & 8 & 0 & \multirow{2}{*}{10.208} & \multirow{2}{*}{.001} & 8 & 4 & \multirow{2}{*}{1.875} & \multirow{2}{*}{.171} \\
\hline & Survival & 2 & 10 & & & 2 & 6 & & \\
\hline \multirow{2}{*}{$72 \mathrm{~h}$} & Death & 8 & 0 & \multirow{2}{*}{10.208} & \multirow{2}{*}{.001} & 8 & 4 & \multirow{2}{*}{1.875} & \multirow{2}{*}{.171} \\
\hline & Survival & 2 & 10 & & & 2 & 6 & & \\
\hline
\end{tabular}

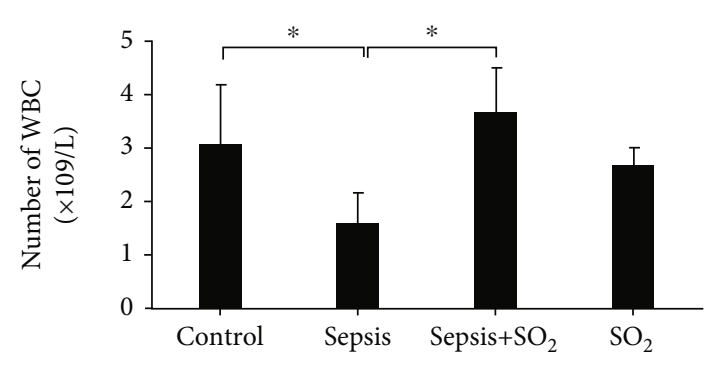

Figure 2: Number of WBCS in each group $\left(\times 10^{9} / \mathrm{L}\right) .{ }^{*} p<0.05$.

Compared with sepsis group, the percentage of blood neutrophils in sepsis $+\mathrm{SO}_{2}$ group was higher $(p=0.000$, Figure 3).

3.3. Morphology of Lung Tissue in Rats of Each Group under Light Microscope. Under the light microscope, the lung tissue in control group was roughly normal, the alveolar walls were intact, no obvious secretions were seen in the alveolar cavity, and there was no inflammatory cell infiltration and red blood cell exudation. In sepsis group, changes in lung tissue occurred. The alveolar structure was incomplete. The alveolar compartment was thickened. As for lung intersti-

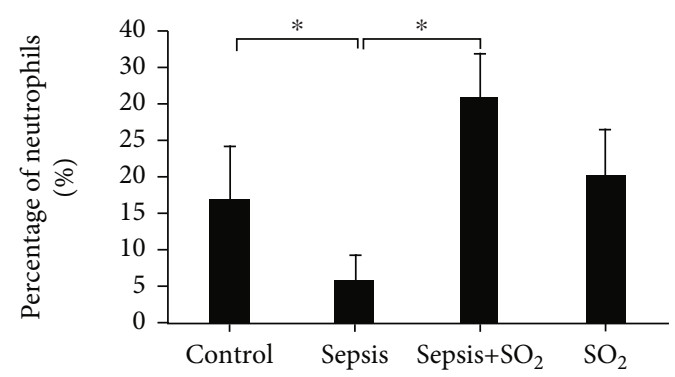

Figure 3: Percentage of neutrophils in each group (\%). ${ }^{*} p<0.05$.

tium and alveolar edema, compared with sepsis group, the alveolar structure of sepsis $+\mathrm{SO}_{2}$ group was more complete, the alveolar interval narrowed, and the interstitial edema was reduced (Figure 4).

3.4. IQA of Lung Tissue in Each Group. IQA of lung tissue in control group, sepsis group, sepsis $+\mathrm{SO}_{2}$ group, and $\mathrm{SO}_{2}$ group was $4.71 \pm 1.380,5.43 \pm 1.512,3.33 \pm 0.516$, and $4.28 \pm 0.756$, respectively. IQA of lung injury in sepsis group was increased compared with control group $(p=0.253)$. While compared with sepsis group, IQA of lung injury in sepsis $+\mathrm{SO}_{2}$ group was reduced $(p=0.003$, Figure 5). 


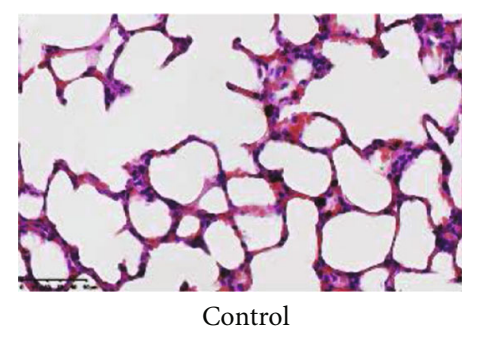

(a)

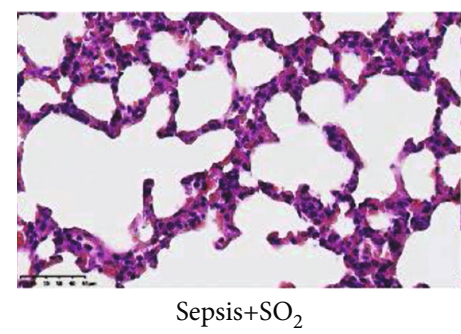

(c)

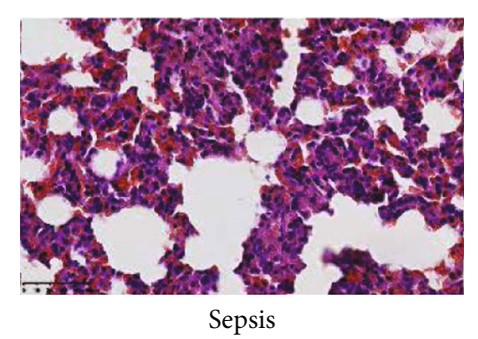

(b)

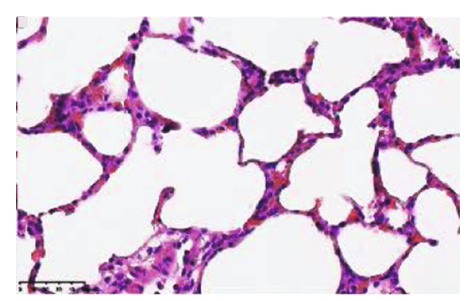

$\mathrm{SO}_{2}$

(d)

FIgURE 4: Microphotographs of morphological change of lung tissues $(\times 40)$. Hematoxylin and eosin staining: (a) control, (b) sepsis, (c) sepsis $+\mathrm{SO}_{2}$, and (d) $\mathrm{SO}_{2}$.

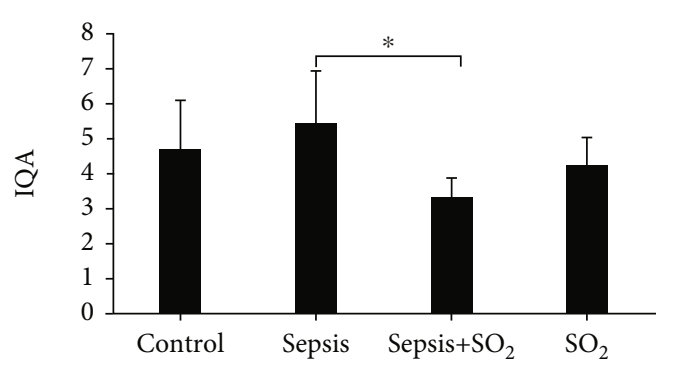

FIgURe 5: IQA of lung tissue in each group. ${ }^{*} p<0.05$.

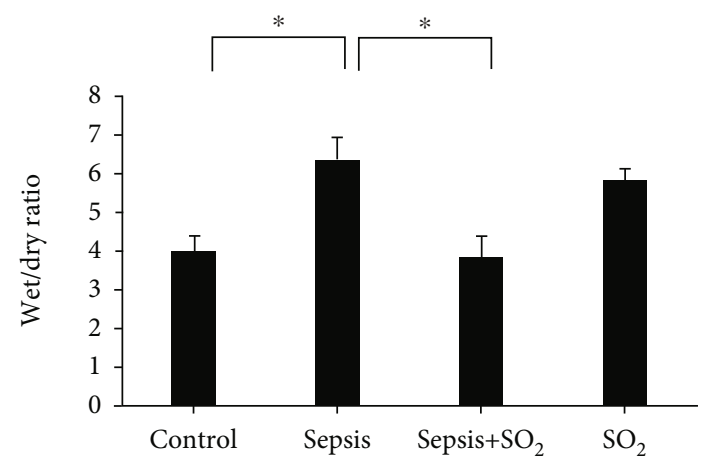

Figure 6: The ratios of $W / D$ of lung tissue in each group. ${ }^{*} p<0.05$.

3.5. Ratios of W/D of Lung Tissue in Each Group. Ratios of $W / D$ of lung tissue in control group, sepsis group, sepsis $+\mathrm{SO}_{2}$ group, and $\mathrm{SO}_{2}$ group were $3.90 \pm 0.334,6.32 \pm$ $0.393,3.82 \pm 0.514$, and $5.83 \pm 0.282$, respectively. The $W /$ $D$ of lung tissue in sepsis group increased compared with control group $(p=0.000)$. The $W / D$ of lung tissue in sepsis $+\mathrm{SO}_{2}$ group was lower compared with sepsis group $(p=0.000$, Figure 6).

\subsection{Oxidation System Indicators in Plasma and Lung Tissues in Each Group}

3.6.1. Levels of $\mathrm{H}_{2} \mathrm{O}_{2}$ in Plasma and Lung Tissues in Each Group. Levels of $\mathrm{H}_{2} \mathrm{O}_{2}$ in plasma in control group, sepsis group, sepsis $+\mathrm{SO}_{2}$ group, and $\mathrm{SO}_{2}$ group were $53.8 \pm 10.1$ $\mathrm{mmol} / \mathrm{L}, 98.4 \pm 37.4 \mathrm{mmol} / \mathrm{L}, 43.1 \pm 9.22 \mathrm{mmol} / \mathrm{L}$, and 44.7 $\pm 14.0 \mathrm{mmol} / \mathrm{L}$, respectively. Levels of $\mathrm{H}_{2} \mathrm{O}_{2}$ in lung tissues in control group, sepsis group, sepsis $+\mathrm{SO}_{2}$ group, and $\mathrm{SO}_{2}$ group were $0.513 \pm 0.0602 \mathrm{mmol} / \mathrm{g}, 0.671 \pm 0.0307 \mathrm{mmol} / \mathrm{g}$, $0.586 \pm 0.0227 \mathrm{mmol} / \mathrm{g}$, and $0.630 \pm 0.0180 \mathrm{mmol} / \mathrm{g}$, respectively. Levels of $\mathrm{H}_{2} \mathrm{O}_{2}$ in plasma and lung tissues in sepsis group increased compared with the control group ( $p=0.001, p=0.000$, respectively). Levels of $\mathrm{H}_{2} \mathrm{O}_{2}$ in plasma and lung tissues in sepsis $+\mathrm{SO}_{2}$ group were reduced compared with the sepsis group $(p=0.000, p=0.000$, respectively, Figure 7).

3.6.2. Levels of MDA in Plasma and Lung Tissues in Each Group. Levels of MDA in plasma in control group, sepsis group, sepsis $+\mathrm{SO}_{2}$ group, and $\mathrm{SO}_{2}$ group were $2.17 \pm 0.898$ $\mathrm{nmol} / \mathrm{mL}, \quad 3.63 \pm 0.745 \mathrm{nmol} / \mathrm{mL}, \quad 3.27 \pm 0.969 \mathrm{nmol} / \mathrm{mL}$, and $2.29 \pm 0.831 \mathrm{nmol} / \mathrm{mL}$, respectively. Levels of MDA in lung tissues in control group, sepsis group, sepsis $+\mathrm{SO}_{2}$ group, and $\mathrm{SO}_{2}$ group were $1.35 \pm 0.2732 \mathrm{nmol} / \mathrm{mg}, 1.62 \pm$ $0.1445 \mathrm{nmol} / \mathrm{mg}, 1.48 \pm 0.0885 \mathrm{nmol} / \mathrm{mg}$, and $1.36 \pm 0.0843$ $\mathrm{nmol} / \mathrm{mg}$, respectively. Compared with control group, levels of MDA in plasma and lung tissues in sepsis group increased $(p=0.004, p=0.007$, respectively). Compared with sepsis group, levels of MDA in plasma and lung tissues in sepsis $+\mathrm{SO}_{2}$ group also showed a decreasing trend $(p=0.450, p=$ 0.000, respectively, Figure 8).

3.6.3. Levels of NO in Plasma and Lung Tissues in Each Group. Levels of NO in plasma in control group, sepsis group, sepsis $+\mathrm{SO}_{2}$ group, and $\mathrm{SO}_{2}$ group were $12.62 \pm 1.34$ 


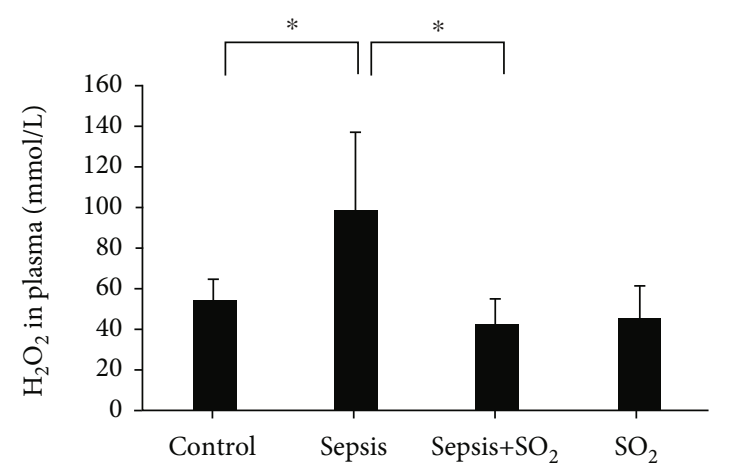

(a)

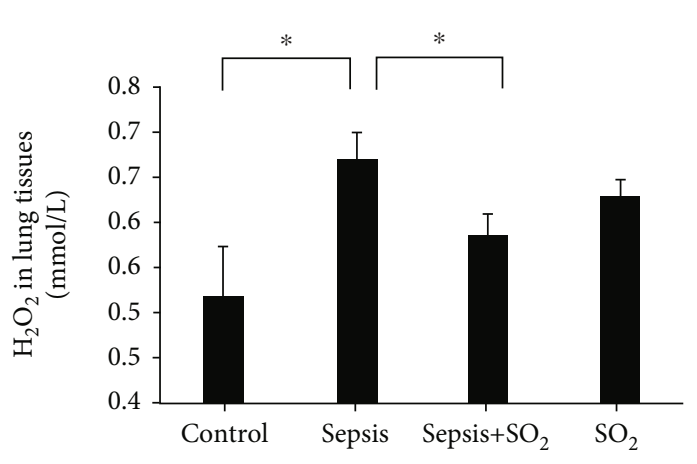

(b)

Figure 7: Levels of $\mathrm{H}_{2} \mathrm{O}_{2}$ in plasma and lung tissues in each group (mmol/L). (a) Plasma; (b) lung tissues. ${ }^{*} p<0.05$.

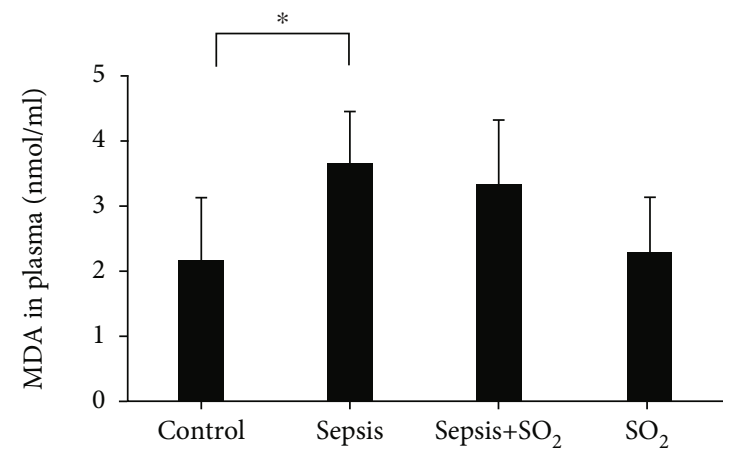

(a)

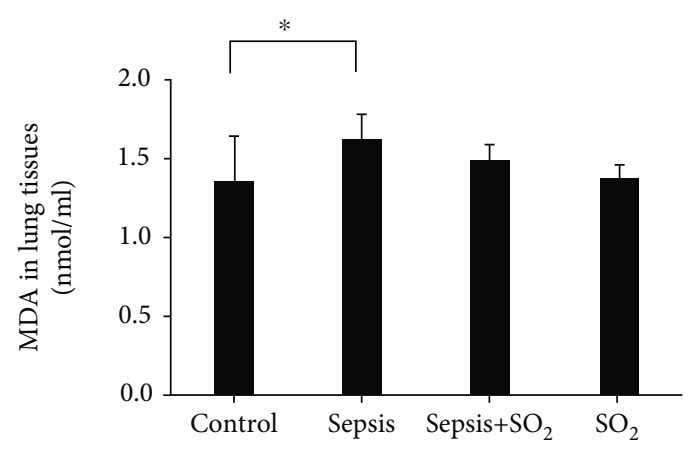

(b)

Figure 8: Levels of MDA in plasma and lung tissues in each group (nmol/mL). (a) Plasma; (b) lung tissues. ${ }^{*} p<0.05$.

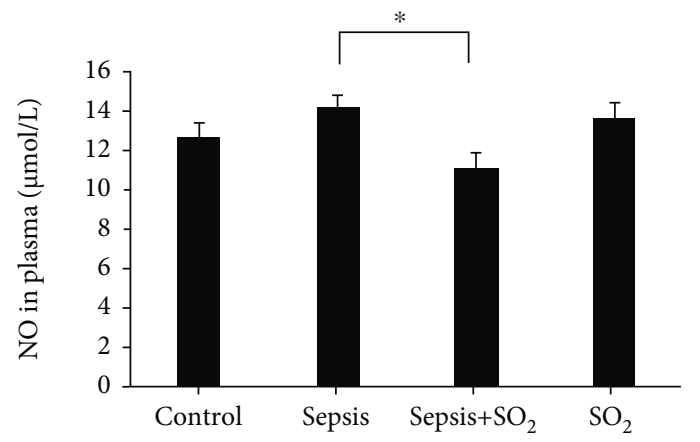

(a)

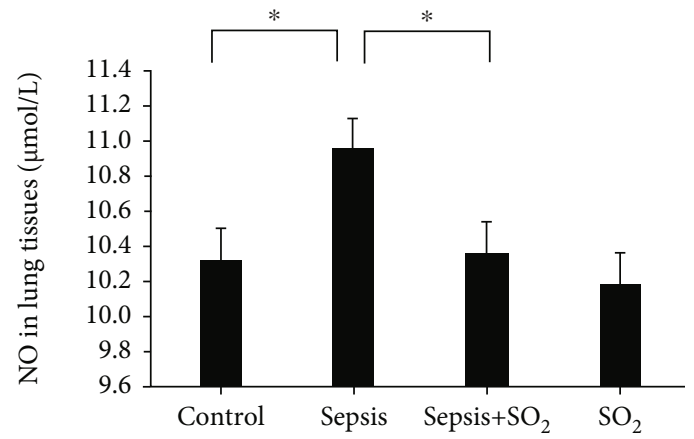

(b)

FIgURE 9: Levels of NO in plasma and lung tissues in each group ( $\mu \mathrm{mol} / \mathrm{L})$. (a) Plasma; (b) lung tissues. ${ }^{*} p<0.05$.

$\mu \mathrm{mol} / \mathrm{L}, \quad 14.10 \pm 1.42 \mu \mathrm{mol} / \mathrm{L}, \quad 11.12 \pm 1.11 \mu \mathrm{mol} / \mathrm{L}, \quad$ and $13.68 \pm 2.32 \mu \mathrm{mol} / \mathrm{L}$, respectively. Levels of $\mathrm{NO}$ in lung tissues in control group, sepsis group, sepsis $+\mathrm{SO}_{2}$ group, and $\mathrm{SO}_{2}$ group were $10.3 \pm 0.894 \mathrm{mmol} / \mathrm{g}, 11.0 \pm 0.360 \mathrm{mmol} / \mathrm{g}$, $10.4 \pm 0.327 \mathrm{mmol} / \mathrm{g}$, and $10.2 \pm 0.152 \mathrm{mmol} / \mathrm{g}$, respectively. Levels of NO in plasma and lung tissues in sepsis group also showed an increasing trend compared with the control group ( $p=0.100, p=0.032$, respectively). Compared with sepsis group, levels of $\mathrm{NO}$ in plasma and lung tissues in sepsis $+\mathrm{SO}_{2}$ group were lower $(p=0.002, p=0.049$, respectively, Figure 9).
3.6.4. Levels of MPO in Plasma and Lung Tissues in Each Group. Levels of MPO in plasma in control group, sepsis group, sepsis $+\mathrm{SO}_{2}$ group, and $\mathrm{SO}_{2}$ group were $51.8 \pm$ $25.5 \mathrm{U} / \mathrm{L}, 85.1 \pm 52.2 \mathrm{U} / \mathrm{L}, 38.1 \pm 9.89 \mathrm{U} / \mathrm{L}$, and $50.3 \pm 19.5$ $\mathrm{U} / \mathrm{L}$, respectively. Levels of MPO in lung tissues in control group, sepsis group, sepsis $+\mathrm{SO}_{2}$ group, and $\mathrm{SO}_{2}$ group were $4.05 \pm 3.084 \mathrm{U} / g, 8.26 \pm 0.637 \mathrm{U} / g, 6.11 \pm 0.195 \mathrm{U} / \mathrm{g}$, and $6.88 \pm 0.444 \mathrm{U} / \mathrm{g}$, respectively. Compared with control group, levels of MPO in plasma and lung tissues in sepsis group showed an increasing trend $(p=0.056, p=0.000$, respectively). Compared with sepsis group, MPO level in 


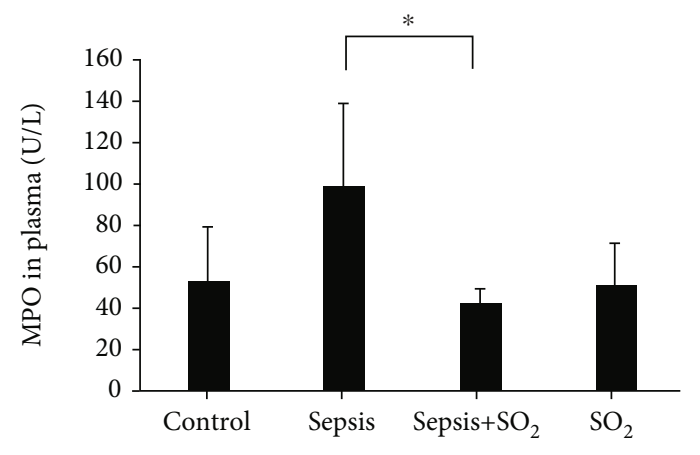

(a)

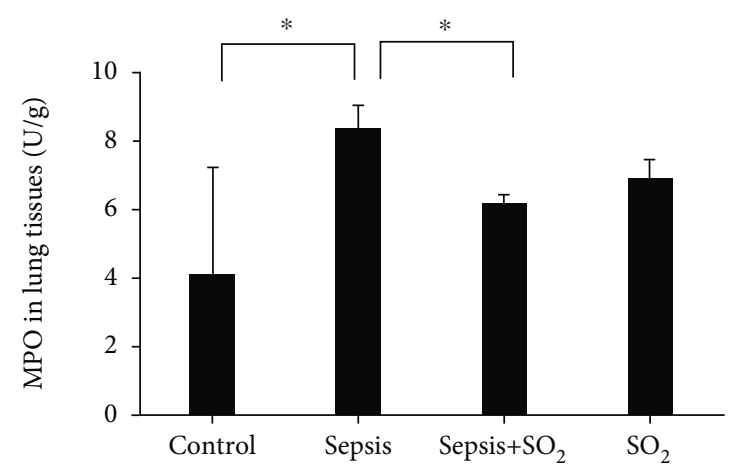

(b)

Figure 10: Levels of MPO in plasma and lung tissues in each group (U/L). (a) Plasma; (b) lung tissues. ${ }^{*} p<0.05$.

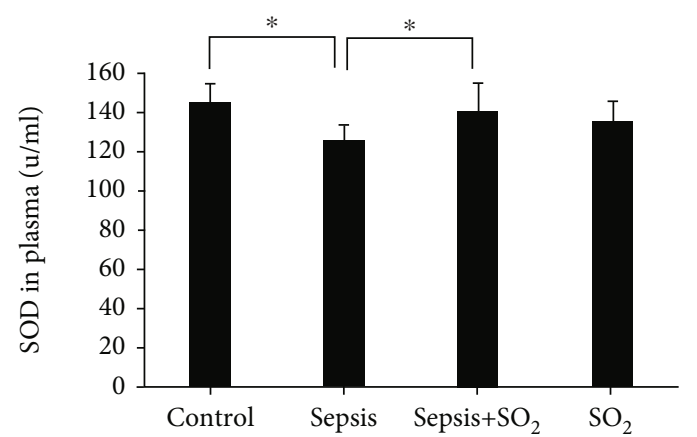

(a)

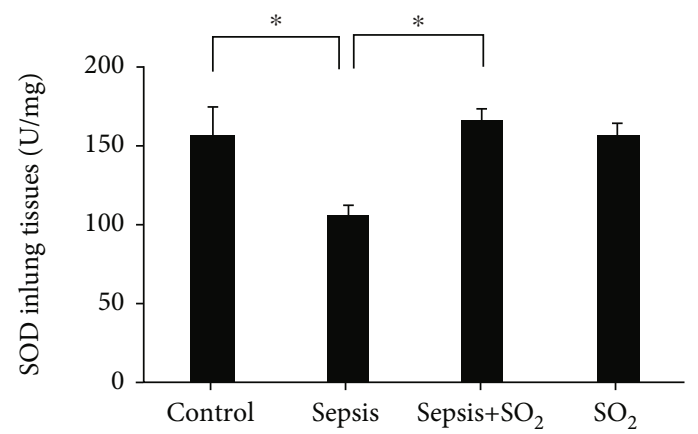

(b)

FIgURe 11: Levels of SOD in plasma and lung tissues in each group (U/mL). (a) Plasma; (b) lung tissues. ${ }^{*} p<0.05$.

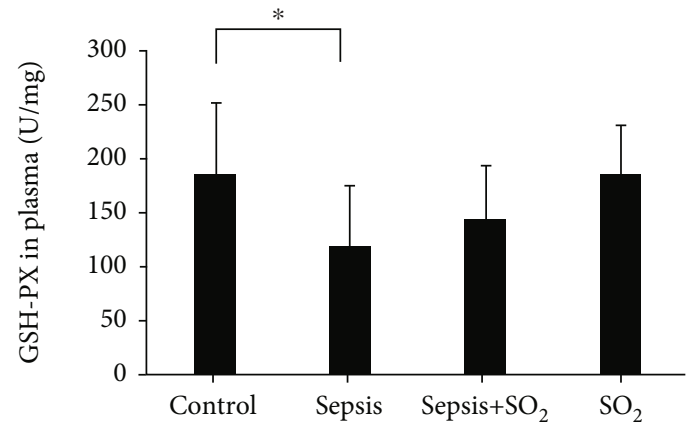

(a)

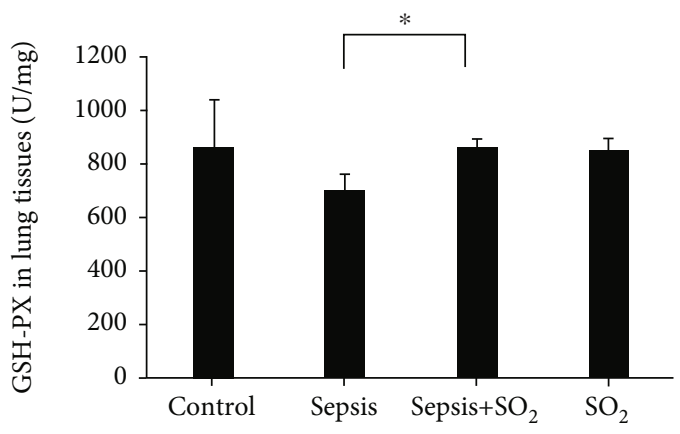

(b)

Figure 12: Levels of GSH-px in plasma and lung tissues in each group (U/mL). (a) Plasma; (b) lung tissues. * $p<0.05$.

plasma and lung tissues in sepsis $+\mathrm{SO}_{2}$ group were significantly lower $(p=0.009, p=0.027$, respectively, Figure 10$)$.

\subsection{Antioxidant System Indicators in Plasma and Lung Tissues in Each Group}

3.7.1. Levels of SOD in Plasma and Lung Tissues in Each Group. Levels of SOD in plasma in control group, sepsis group, sepsis $+\mathrm{SO}_{2}$ group, and $\mathrm{SO}_{2}$ group were $143 \pm 9.45 \mathrm{U}$ $/ \mathrm{mL}, 124 \pm 6.46 \mathrm{U} / \mathrm{mL}, 138 \pm 14.22 \mathrm{U} / \mathrm{mL}$, and $134 \pm 8.91 \mathrm{U}$ $/ \mathrm{mL}$, respectively. Levels of SOD in lung tissues in control group, sepsis group, sepsis $+\mathrm{SO}_{2}$ group, and $\mathrm{SO}_{2}$ group were
$156.0 \pm 17.70 \mathrm{U} / \mathrm{mg}, 106.2 \pm 5.25 \mathrm{U} / \mathrm{mg}, 165.9 \pm 6.46 \mathrm{U} / \mathrm{mg}$, and $157.0 \pm 7.13 \mathrm{U} / \mathrm{mg}$, respectively. Levels of SOD level in plasma and lung tissues in sepsis group decreased compared with control group ( $p=0.003, p=0.001$, respectively). SOD level in plasma and lung tissues in sepsis $+\mathrm{SO}_{2}$ group increased compared with sepsis group $(p=0.021, p=0.000$, respectively, Figure 11).

3.7.2. Levels of GSH-Px in Plasma and Lung Tissues in Each Group. Levels of GSH-px in plasma in control group, sepsis group, sepsis $+\mathrm{SO}_{2}$ group, and $\mathrm{SO}_{2}$ group were $186 \pm 64.7 \mathrm{U}$ $/ \mathrm{mL}, 118 \pm 56.2 \mathrm{U} / \mathrm{mL}, 147 \pm 47.2 \mathrm{U} / \mathrm{mL}$, and $186 \pm 44.6 \mathrm{U} /$ 


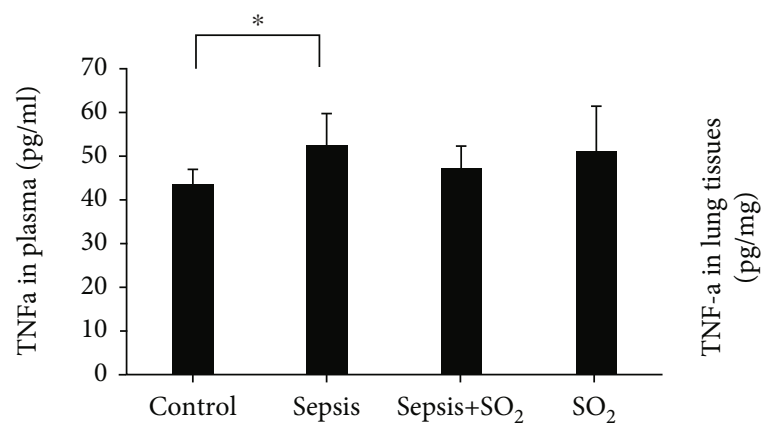

(a)

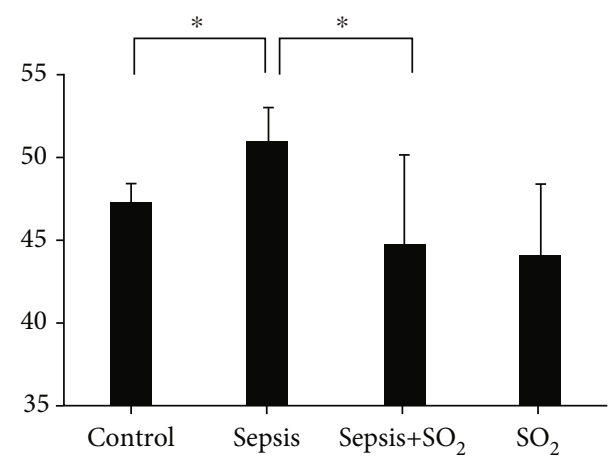

(b)

Figure 13: Levels of TNF- $\alpha$ in plasma and lung tissues in each group. (a) Plasma; (b) lung tissues. ${ }^{*} p<0.05$.

$\mathrm{mL}$, respectively. Levels of GSH-px in lung tissues in control group, sepsis group, sepsis $+\mathrm{SO}_{2}$ group, and $\mathrm{SO}_{2}$ group were $41.1 \pm 7.33 \mathrm{U} / \mathrm{mg}, 51.2 \pm 1.92 \mathrm{U} / \mathrm{mg}, 45.0 \pm 5.13 \mathrm{U} / \mathrm{mg}$, and $44.2 \pm 4.30 \mathrm{U} / \mathrm{mg}$, respectively. Compared with control group, levels of GSH-px in plasma and lung tissues in sepsis group decreased ( $p=0.027, p=0.295$, respectively). Compared with sepsis group, levels of GSH-px in sepsis $+\mathrm{SO}_{2}$ group also showed an increasing trend $(p=0.333, p=0.001$ , respectively, Figure 12).

3.8. Levels of TNF- $\alpha$ in Plasma and Lung Tissues in Each Group. Levels of TNF- $\alpha$ in plasma and lung tissues in control group, sepsis group, sepsis $+\mathrm{SO}_{2}$ group, and $\mathrm{SO}_{2}$ group were $43.8 \pm 2.94 \mathrm{pg} / \mathrm{mL}, 52.2 \pm 7.50 \mathrm{pg} / \mathrm{mL}, 47.6 \pm 4.59 \mathrm{pg} /$ $\mathrm{mL}$, and $50.8 \pm 10.60 \mathrm{pg} / \mathrm{mL}$, respectively. Levels of TNF- $\alpha$ in lung tissues in control group, sepsis group, sepsis $+\mathrm{SO}_{2}$ group, and $\mathrm{SO}_{2}$ group were $41.1 \pm 7.33 \mathrm{pg} / \mathrm{mg}, 48.5 \pm 2.80$ $\mathrm{pg} / \mathrm{mg}, 45.0 \pm 5.13 \mathrm{pg} / \mathrm{mg}$, and $44.2 \pm 4.30 \mathrm{pg} / \mathrm{mg}$, respectively. Compared with control group, levels of TNF- $\alpha$ in plasma and lung tissues in sepsis group increased $(p=0.035, p=0.001$, respectively). Compared with sepsis group, levels of TNF- $\alpha$ in sepsis $+\mathrm{SO}_{2}$ group also showed an decreasing trend $(p=0.236, p=0.040$, respectively, Figure 13).

\section{Discussion}

Sepsis is a common and critical complication, which could be induced by severe trauma, injury, shock, or major surgery. Sepsis may develop into septic shock. Though clinical technology develops fast, the high morbidity and mortality of sepsis is still a major problem [6,7]. Previous studies have shown that septic lung injury can lead to the interaction of cAMP and various hormone levels, resulting in changes in lung tissue structure [8-12]. In this study, the survival rate of $40 \mathrm{SD}$ rats was studied through the CLP sepsis model. The result suggested that the survival rate of septic rats decreased after 24 hours, and the final survival rate was only $20 \%$. Li et al. found that the mortality rate of sepsis rat models began to decrease from 24 hours after the operation and finally reached $30 \%$, which was consistent with the result of this research [13]. The result suggested that the survival rate in sepsis group was reduced. The survival rate was increased to $60 \%$ after the intervention of sulfur dioxide. The results demonstrated that sulfur dioxide can increase the survival rate of sepsis rates and reduce the mortality rate during the onset of sepsis. At the same time, this study established a CLP model in 28 rats, and the number of WBC and the percentage of neutrophils in the sepsis group were reduced. This result has the same means as that reported by Wang LY, suggesting that the CLP sepsis model in this study was successfully made [13-15].

Lung tissue is the common easily affected organ in sepsis, causing septic lung injury [16]. Septic lung injury is an important complication of sepsis, with the highest death ratio, and it is also an important reason for death from sepsis $[17,18]$. In this study, after cecal ligation and perforation were given to male rats, under a light microscope, the following could be observed: the lung tissue structure was incomplete, lung capillary permeability increased, alveolar septum thickened, lung interstitium increased, and alveolar edema occurred. The semiquantitative score of lung tissue increased. Deng et al. also found the increase of IQA of lung tissues [14]. The $W / D$ ratio of lung tissue increased. These changes are consistent with the pathological process of acute lung injury and once again confirmed that sepsis can be caused by acute lung injury. Endogenous sulfur dioxide may play a protective role in lung injury as found in previous studies [19]. In this study, after the endogenous $\mathrm{SO}_{2}$ donor $\mathrm{Na}_{2} \mathrm{SO}_{3} / \mathrm{NaHSO}_{3}$ was given, the lung tissue structure, lung capillary permeability, and the obvious thickening of the alveolar compartment were all improved; the wet weight/ dry weight ratio of lung tissue and the histology of lung injury was improved. The IQA were lower than before, also confirming that $\mathrm{SO}_{2}$ is a protective role during lung injury induced by sepsis.

The imbalance between oxidation and antioxidants in the oxidative stress response is a major mechanism during septic lung injury and chronic obstructive pulmonary disease [20]. This study also found that the oxidation system indicators of the oxidative stress response in sepsis group including $\mathrm{H}_{2} \mathrm{O}_{2}$, MDA, NO level, and MPO activity increased compared with the control group. This result is the same as the results of Rasooli et al. [21], antioxidant system indicators including SOD activity and GSH-px level are reduced, and the above results are consistent with previous 
research results [22-24], once again confirming that oxidation and antioxidant imbalance take part in the pathogenesis of septic lung injury. Other studies have also confirmed that sulfur dioxide could regulate the oxidative stress response $[25,26]$. In this study, it was found that after sulfur dioxide intervention, the oxidation system indicators $\mathrm{H}_{2} \mathrm{O}_{2}, \mathrm{MDA}$, NO level, and MPO activity decreased. The antioxidant system indicators including SOD activity and GSH-px level raised. The results show that sulfur dioxide can protect lung tissue by improving the oxidation and antioxidant effects of sepsis.

In the pathological process of sepsis, TNF- $\alpha$ can induce the release of downstream inflammatory mediators to cause oxidative stress imbalance. At the same time, our research found that the content of TNF- $\alpha$ is significantly increased during lung injury. In the sepsis $+\mathrm{SO}_{2}$ group, levels of TNF$\alpha$ in plasma and lung tissue were reduced, and the oxidative stress index was significantly improved compared with the sepsis group. These results suggest that the administration of $\mathrm{SO}_{2}$ can inhibit the expression of TNF- $\alpha$ in the case of sepsis lung injury. Inhibit the oxidative stress response, thereby playing a protective role in septic lung injury.

In summary, sulfur dioxide can improve the survival rate of sepsis by reducing lung injury caused by sepsis, and its mechanism is related to inhibition of the oxidation effect induced by sepsis during lung injury and improving antioxidant effect. This discovery deepens the understanding of sepsis in clinical work and provides new ideas for the treatment of sepsis and the development of new drugs. However, this study did not explore more specific mechanisms. These specific mechanisms need to be carried out in future research.

\section{Data Availability}

The data used to support the findings of this study are included within the article.

\section{Conflicts of Interest}

The authors declare that they have no conflicts of interest.

\section{Authors' Contributions}

Zhiwei Liu and Jiaqi Gao contributed equally to this work.

\section{Acknowledgments}

This project is funded by the Beijing Jishuitan Hospital Natural Fund Cultivation Project Fund (ZR-201927).

\section{References}

[1] M. Cecconi, L. Evans, M. Levy, and A. Rhodes, "Sepsis and septic shock," Lancet, vol. 392, no. 10141, pp. 75-87, 2018, Epub 2018 Jun 21.

[2] Y. Q. Huang, H. F. Jin, H. Zhang, C. S. Tang, and J. B. Du, "Interaction among hydrogen sulfide and other gasotransmitters in mammalian physiology and pathophysiology," Advances in Experimental Medicine and Biology, vol. 1315, pp. 205-236, 2021.
[3] Y. Zhai, X. L. Huang, H. J. Ma, X. H. Zhou, J. L. Zhou, and Y. M. Fan, "Sulfur dioxide reduces lipopolysaccharideinduced acute lung injury in rats," Central-European Journal of Immunology, vol. 44, no. 3, pp. 226-236, 2019.

[4] Y. R. Zhao, Y. Liu, D. Wang, W. R. Lv, and J. L. Zhou, "Effects of sulfur dioxide on alveolar macrophage apoptosis in acute lung injury induced by limb ischemia/reperfusion in rats," Beijing Da Xue Xue Bao Yi Xue Ban, vol. 51, no. 2, pp. 239-244, 2019.

[5] W. Gong and H. Wen, "Sepsis induced by cecal ligation and puncture," Methods in Molecular Biology, vol. 2019, pp. 249255, 2019.

[6] C. Chiu and M. Legrand, "Epidemiology of sepsis and septic shock," Current Opinion in Anaesthesiology, vol. 34, no. 2, pp. 71-76, 2021.

[7] P. Arina and M. Singer, "Pathophysiology of sepsis," Current Opinion in Anaesthesiology, vol. 34, no. 2, pp. 77-84, 2021.

[8] K. Hsu, D. Wang, C. Y. Shen, and C. H. Chiang, "Protamineinduced acute lung injury and the protective effect of agents that increase cAMP," Proceedings of the National Science Council, Republic of China. Part B, vol. 17, no. 2, pp. 57-61, 1993.

[9] B. M. Nabishah, B. A. Khalid, P. B. Morat, A. K. Alias, and M. Zainuddin, "Effects of steroid hormones on cyclic adenosine 3',5'-monophosphate levels in the rat lung," The Journal of Endocrinology, vol. 134, no. 1, pp. 73-76, 1992.

[10] B. H. Ruszymah, B. M. Nabishah, S. Aminuddin, and B. A. Khalid, "Effects of glycyrrhizic acid on right atrial pressure and pulmonary vasculature in rats," Clinical and Experimental Hypertension, vol. 17, no. 3, pp. 575-591, 1995.

[11] B. M. Nabishah, P. B. Morat, A. K. Alias, B. A. Kadir, and B. A. Khalid, "Cyclic adenosine 3',5'-monophosphate content and bronchial smooth muscle contractility of hyper- and hypothyroid lungs," Clinical and Experimental Pharmacology \& Physiology, vol. 19, no. 12, pp. 839-842, 1992.

[12] B. M. Nabishah, Z. Merican, P. B. Morat, A. K. Alias, and B. A. Khalid, "Effects of steroid hormones pretreatment on isoprenaline-induced cyclic adenosine $3^{\prime}, 5^{\prime}$-monophosphate in rat lung," General Pharmacology, vol. 21, no. 6, pp. 935938, 1990.

[13] J. L. Li, G. Li, X. Z. Jing et al., "Assessment of clinical sepsisassociated biomarkers in a septic mouse model," Journal of International Medical Research, vol. 46, no. 6, pp. 2410-2422, 2018.

[14] Q. Deng, T. Zhao, B. Pan et al., "Protective effect of tubastatin A in CLP-induced lethal sepsis," Inflammation, vol. 41, no. 6, pp. 2101-2109, 2018.

[15] R. Guo, Y. Li, M. Han, J. Liu, and Y. Sun, "Emodin attenuates acute lung injury in cecal-ligation and puncture rats," International Immunopharmacology, vol. 85, p. 106626, 2020, Epub 2020 May 31

[16] V. Kumar, "Pulmonary innate immune response determines the outcome of inflammation during pneumonia and sepsisassociated acute lung injury," Frontiers in immunology, vol. 11, p. 1722, 2020.

[17] H. Zhao, H. Chen, M. Xiaoyin et al., "Autophagy activation improves lung injury and inflammation in sepsis," Inflammation, vol. 42, no. 2, pp. 426-439, 2019.

[18] L. Yang, S. Liu, S. Han et al., "The HDL from septic-ARDS patients with composition changes exacerbates pulmonary endothelial dysfunction and acute lung injury induced by cecal ligation and puncture (CLP) in mice," Respiratory Research, vol. 21 , no. 1, p. 293, 2020. 
[19] E. Wigenstam, L. Elfsmark, L. Ågren, C. Akfur, A. Bucht, and S. Jonasson, "Anti-inflammatory and anti-fibrotic treatment in a rodent model of acute lung injury induced by sulfur dioxide," Clinical Toxicology, vol. 56, no. 12, pp. 1185-1194, 2018, Epub 2018 Jun 20.

[20] Y. Xu, H. Liu, and L. Song, "Novel drug delivery systems targeting oxidative stress in chronic obstructive pulmonary disease: a review," Journal of nanobiotechnology, vol. 18, no. 1, p. 145, 2020.

[21] A. Rasooli, E. Ghafari, H. Saedi, and S. Miri, "Expression changes of CD177 and MPO as novel biomarkers in lung tissue of CLP model rats," Turkish journal of medical sciences, vol. 48, no. 6, pp. 1321-1327, 2018.

[22] M. Aziz, Y. Ode, M. Zhou et al., "B-1a cells protect mice from sepsis-induced acute lung injury," Molecular Medicine, vol. 24, no. 1, p. 26, 2018.

[23] H. Fu, J. Zhang, and M. Huang, "Topiroxostat ameliorates oxidative stress and inflammation in sepsis-induced lung injury," Zeitschrift für Naturforschung C, vol. 75, no. 11-12, pp. 425431, 2020.

[24] T. Li, Y. N. Wu, H. Wang, J. Y. Ma, S. S. Zhai, and J. Duan, “_Dapk1_ improves inflammation, oxidative stress and autophagy in LPS-induced acute lung injury via p38MAPK/ NF- $\kappa \mathrm{B}$ signaling pathway," Molecular Immunology, vol. 120, pp. 13-22, 2020, Epub 2020 Feb 8.

[25] Y. Huang, H. Zhang, B. Lv, C. Tang, J. Du, and H. Jin, "Sulfur dioxide: endogenous generation, biological effects, detection, and therapeutic potential," Antioxid Redox Signal, vol. 36, no. 4-6, pp. 256-274, 2022.

[26] S. Zhu, L. Zhao, Y. Fan et al., "Interaction between TNF- $\alpha$ and oxidative stress status in first-episode drug- naive schizophrenia," Psychoneuroendocrinology, vol. 114, p. 104595, 2020, Epub 2020 Jan 30. 